\title{
Impacts of External Built Residential Environment that is Associated with Anxiety Disorders of Children
}

\author{
Charles Ochodo ${ }^{1 *}$, David M. Ndetei ${ }^{2}$, Wilkister N. Moturi ${ }^{1}$, Joseph O. Otieno ${ }^{3}$ \\ ${ }^{1}$ Department of Environmental Science, Egerton University, Kenya \\ ${ }^{2}$ Department of Psychiatry, University of Nairobi, Kenya \\ ${ }^{3}$ Department of Geography, Egerton, University, Kenya
}

Received: November 06, 2015; Accepted: December 27, 2015; Published: December 31, 2015

*Corresponding author: Charles Ochodo, Department of Environmental Science, Egerton University, P.O Box 536, Egerton-Njoro, Kenya, Tel: +254722-439224; E-mail: ochodoc@yahoo.com

\begin{abstract}
Built residential environment characterized by poor quality housing, poor sanitation and underdeveloped infrastructure, among other attributes, adversely impact the mental health of children. This study looked into the relationship between characteristics of urban built external residential environment and anxiety disorders of children in selected residences of Nakuru municipality in Kenya. Built external residential environment characteristics were investigated for 283 children in different residential settings that were categorized by their socio-economic-status. Medically validated interview schedules were used to determine mental health of children in the respective neighborhoods. The researchers noted a higher likelihood of panic disorder, agoraphobia, separation anxiety disorder, obsessive compulsive disorder and generalized anxiety disorder in children who were regularly exposed to poor external built residential environment. Thus characteristics of the built external residential environment are important factors in the lives of children as they have significant impact on their mental health.
\end{abstract}

Keywords: Adverse impacts; Children; External built environment; Mental health; Socio-Economic- Status

\section{Introduction}

Knowledge of the relationship between characteristics of children's urban built external residential environment and their mental health is of immense value in deciding appropriate conditions for their development. Good mental health in children is a prerequisite for their optimal emotional and psychological development, productive social relationships, effective learning, and ability to care for oneself, good physical health and socioeconomic participation as adults [1].

Inequities in construction and maintenance of low-income housing result in insufficient housing, poor quality housing, overcrowding, higher levels of population density and health problems [2] Residents may experience an increase in incidents of mental illness and poor physical health. According to Gifford, [3] high rise multiple dwellings affect the psychological wellbeing of mothers with young children and possibly that of young children themselves. The effects are particularly pronounced among lowincome families. Suspected reasons for the link between high-rise housing and psychological distress are social isolation of mothers and restricted play opportunities for children.

Parents of young children in large multiple-dwelling units often cope with the inadequacy of available play spaces by keeping children inside their apartments. Such restrictions heighten intra-familial conflict, minimize play opportunities with others and restrict a primary avenue of parents to know their neighbors [4].

Environmental features that aggravate stress include crowding, prominent litter, unaesthetic built facilities and intrusive or incongruent sounds [5]. Such environments can affect both mental and physical health through a reduction in physical activity, increased anxiety and social disorder among residents [6]. Overcrowded housing conditions contribute to higher mortality rates, stress, infectious disease risk and poor childhood development. Overcrowding is a major problem of the built environment especially in slums and squalid environments. It arises from poverty, overpopulation and inefficient accommodation. It is a problem that has social and health effects [7].

Leventhal, et al. [8] argues that neighborhood quality has mental health impacts on children and their families independent of household Socio-Economic Status (SES). Living in greener environments is associated with better mental health and higher scores in general health questionnaires [9]. People are more likely to exercise if the external environment factors including access roads are attractive, safe, unobstructed and project enjoyable scenery.

A disproportionate burden of ill health associated with the built environment is borne by certain groups within the population; the least well off people in society tend to suffer more from poorer health [10]. Poor people are more likely to live in poor quality environments that contribute to poor health. Children and the elderly are particularly vulnerable to 
the adverse effects of poor quality built environment. Effective planning for public health involves provision of healthy human habitats and supportive social structures [11].

\section{Methods}

The study used a cross-sectional social survey of children in the low, middle and high income neighborhoods of Nakuru Municipality; 283 children within the age range of 10-17 years and 11 months were randomly selected in the low, middle and high income residential areas. Respondents were selected on the basis of living in a given neighborhood for more than one year. Studies by Evans, et al. and Lepore, et al. [12,13] have shown that after living in a given neighborhood for more than six months, residents exhibit behavior and health states that demonstrate successful or unsuccessful adjustment to prevailing environmental characteristics.

Respondents were interviewed using structured questionnaires for environmental characteristics and validated lay mental health instruments for mental health: the Mini International Neuropsychiatric Interview for Children and Adolescents (M.I.N.I-Kid) [14] and Alcohol, Smoking and Substance Involvement Screening Test [15].

Permission for the research was obtained from a recognized research and ethics board: the Kenyatta National Hospital Ethics Review Board. The study involved visiting households hence permission was obtained from household heads before entry into the houses. Informed consent to interview the children was sought from their parents or guardians after an explanation of the nature and objectives of the study. Assent from the participating children was obtained and they were free to withdraw their assent at any time during the study period if they so wished. The identity of children who participated in this study will not be known by any third party. Their names have been coded by use of numbers that will remain known only to the researcher.

\section{Data analysis}

The built external residential environment characteristics across the three categories of residential areas: low, middle and high income were analyzed by the use of descriptive statistics while Chi-square tests $(P \leq 0.05)$ were used to determine the prevalence of specific mental health disorders of respondents. Multi-variable logistic regression $(P \leq 0.05)$ was used to assess the relationship between the urban built external residential environment characteristics and the likelihood of developing specific mental health disorders. Socio-demographic characteristics (age, sex, number of occupants in household and daily food expenditure per person) were controlled for in the model.

\section{Results}

\section{Characteristics of external built residential environment}

The following external environment characteristics were investigated: states of roofs, types of walls, heights of roofs above the ground, residential densities, green spaces and shopping facilities (Table 1).

\section{Heights and states of roofs}

The recommended height of roofs for residential houses should be at least 10 feet above the ground [16]. Houses whose roof heights are less than 10 feet concentrate heat during the day and reduce indoor air circulation thus affecting ventilation. These attributes can engender chronic discomfort that may affect mental health of children. In the low income residences, $98.5 \%$ of the houses had roof heights that were less than 10 feet above the ground compared to the middle and high income ones that had $1.5 \%$ and no house respectively with such heights. Leaking roofs were mainly a feature of the low income neighborhoods.

\section{Crowding}

Population density and the number of dwelling units in a given area determine overcrowding. For multifamily housing units, the recommended number of houses per hectare is: lowdensity-50, medium-density-60, high-density-70 and extreme high density-133. Informal settlements invariably exceed 400 dwelling units per hectare [17]. Overcrowding of dwelling units' causes distress to residents as amenities such as latrines, bathrooms and water are severely deficient. There is lack of space for movement and children's play. Littering of neighbors' frontages occurs, noise pollution, internal insecurity and recurrent disagreements e.g., due to activities of children are common.

Overcrowding of housing units coupled with a high population density and lack of physical planning in the low income neighborhoods contributed to storm and waste water draining into neighbors' frontages or houses. Quite often neighborhood disagreements resulted. These created fear among minors to the extent that some of them did not want to be separated from their parents or guardians. They felt extremely insecure when they had to leave home for other places like school. In the middle income residential areas, frequently, high-rise flats were crammed into

\begin{tabular}{|l|l|l|l|}
\hline \multicolumn{3}{|l|}{ Table 1: Characteristics of the external built residential environment. } \\
\hline $\begin{array}{l}\text { External environment } \\
\text { characteristics }\end{array}$ & $\begin{array}{l}\text { Low } \\
\text { (Residential areas) }\end{array}$ & $\begin{array}{l}\text { Middle } \\
\text { income \% }\end{array}$ & $\begin{array}{l}\text { High income } \\
\%\end{array}$ \\
\hline Housing units: & 74.1 & 13.7 & 12.2 \\
\hline With leaking roofs & 100 & 0.0 & 0.0 \\
\hline $\begin{array}{l}\text { With non-stone walls (mud/ } \\
\text { plastered mud) }\end{array}$ & 98.5 & 1.5 & 0.0 \\
\hline $\begin{array}{l}\text { Whose roof heights above } \\
\text { the ground is }\end{array}$ & 65.7 & 34.3 & 0.0 \\
\hline Less than 10 feet & 64.6 & 27.9 & 7.5 \\
\hline that are overcrowded & 47.4 & 7.4 & 45.3 \\
\hline $\begin{array}{l}\text { Children who are } \\
\text { dissatisfied with }\end{array}$ & & & \\
\hline Available green spaces & $\begin{array}{l}\text { income } \\
\text { dissatisfied with }\end{array}$ & & \\
\hline Shopping facilities & & & \\
\hline
\end{tabular}


a quarter an acre of land leaving little or no room for children's games. The high-income housing units were singly placed in their compounds and hence did not exhibit the features associated with overcrowding.

\section{Green spaces}

Overcrowding of dwelling units also implies that there will be little or no green spaces. These spaces provide aesthetic appeal; grass and flower gardens denote tranquility. According to Ulrich, [18] viewing of plants and flowers ameliorates stress within five minutes or less. Viewing nature for longer periods helps to calm residents and can foster improvement in mental health.

In the middle and high-income housing units, concrete compounds replaced green spaces while in the low-income residential areas, open grounds that generated choking dust in the dry season or gave rise to muddy pathways in the wet season dominated the small restricted compounds.

\section{Shopping facilities}

The low level of dissatisfaction with shopping facilities among the middle-income children was attributed to the availability of shops and supermarkets in the vicinity of their dwelling units. In addition, they had the necessary financial capability to purchase most of the goods in standard packaging sizes. The high-income children expressed dissatisfaction with the few available shopping facilities in their neighborhood. These facilities were found to serve as their centres of social interaction. The lowincome children who had shops and grocery kiosks very close to their door steps could not afford certain items they required.

\section{Prevalence of Mental Health Disorders among Children of the Low, Middle and High-Income Neighborhoods}

\section{Panic disorder}

Whereas the prevalence of panic disorder was relatively low, $16.8 \%$, among children in the low-income residential area, the difference in its prevalence among children across the three categories of neighborhoods was found to be insignificant (Table 2). Likewise, the difference in occurrence of this disorder among children of the low and high-income residential areas was not significant $\left(\chi^{2}=0.885, P=0.347\right)$ as was its difference in prevalence among those of the low and middle-income residential areas $\left(\chi^{2}\right.$ $=0.463, P=0.496$ ).
The level of panic disorder among children of the middle and high income residential areas was found to be insignificant $\left(\chi^{2}=0.067, P=0.796\right)$. In spite of the higher prevalence of panic disorder among the female children in comparison to the male ones, the difference in its prevalence among children of either gender was not significant (Table 3).

Children who lived in houses whose roof heights above the ground were more than ten feet were 0.027 times less likely to develop panic disorder in comparison to those who stayed in houses whose roof heights were less than ten feet above the ground (Table 4). Children who were dissatisfied with shopping facilities in their neighborhoods had a 3.516 units higher likelihood of experiencing panic disorder in relation to those who were satisfied with their neighborhood shopping facilities. The number of occupants within the house was a significant confounder in regard to panic disorder. Children who lived in houses that had less than six occupants were 0.042 times less susceptible to panic disorder.

\section{Agoraphobia}

The middle-income areas showed a significantly higher prevalence of agoraphobia than the high-income ones $\left(\chi^{2}=\right.$ 4.680, $P=0.03)$. The low and middle-income areas $\left(\chi^{2}=1.538\right.$, $P=0.215)$, like the low and high-income ones $\left(\chi^{2}=1.020, P=\right.$ 0.313 ) had insignificant differences in the disorder. Contrary to the prevalence rate of this disorder among adults where more females than males are affected, twice as many male children experienced this disorder in comparison to female ones (Table 3).

Children who lived in houses with intact roofs were 0.318 times less likely to exhibit agoraphobia compared to those who lived in houses with leaking roofs (Table 4). Children who expressed dissatisfaction with shopping facilities in their residential areas were 3.719 times more prone to agoraphobia than those who were satisfied with shopping facilities in their neighborhoods. Sex was a significant confounder in the multivariable logistic regression models that were used in these analyses. Female children were 0.419 times less predisposed to agoraphobia than the males.

\section{Separation anxiety disorder}

Separation Anxiety Disorder was relatively low in children in the high-income residential area (Table 2). This can be attributed

Table 2: Prevalence of children's mental health disorders in the low, middle and high-income residential areas.

\begin{tabular}{|c|c|c|c|c|c|}
\hline \multirow{2}{*}{\begin{tabular}{|l|} 
Mental Health \\
Disorder \\
\end{tabular}} & \multicolumn{3}{|c|}{ (Residential area) } & \multirow{2}{*}{$\begin{array}{l}\text { Chi-square } \\
\left(\chi^{2}\right)\end{array}$} & \multirow[t]{2}{*}{$P \leq 0.05$} \\
\hline & Low Income, \% & Middle Income, \% & High Income, \% & & \\
\hline Panic disorder & 16.8 & 20.6 & 22.2 & 0.935 & 0.63 \\
\hline Agoraphobia & 14.9 & 21.7 & 10.0 & 4.833 & 0.09 \\
\hline${ }^{*} \mathrm{SAD}$ & 14.9 & 14.1 & 7.8 & 2.588 & 0.27 \\
\hline${ }^{*} \mathrm{OCD}$ & 7.9 & 12.0 & 22.2 & 8.574 & 0.014 \\
\hline${ }^{*} \mathrm{GAD}$ & 5.0 & 10.9 & 10.0 & 2.566 & 0.28 \\
\hline
\end{tabular}

*SAD: Separation Anxiety Disorder; OCD: Obsessive Compulsive Disorder; GAD: Generalized Anxiety Disorder 


\begin{tabular}{|l|l|l|l|l|l|}
\hline \multicolumn{2}{|l|}{ Table 3: Prevalence of mental health disorders in male and female children. } \\
\hline Mental health disorder & Males \% & Females \% & Chi-square $\boldsymbol{\chi}^{2}$ ) & P $\mathbf{0 . 0 5}$ \\
\hline Panic disorder & 18.5 & 21.2 & 0.319 & 0.57 \\
\hline Agoraphobia & 20.5 & 10.2 & 5.743 & 0.02 \\
\hline${ }^{*}$ SAD & 11.6 & 13.1 & 0.146 & 0.70 \\
\hline${ }^{*}$ OCD & 14.4 & 13.1 & 0.092 & 0.76 \\
\hline${ }^{*}$ GAD & 10.3 & 6.6 & 1.250 & 0.26 \\
\hline
\end{tabular}

*SAD: Separation Anxiety Disorder; OCD: Obsessive Compulsive Disorder; GAD: Generalized Anxiety Disorder

Table 4: Relationship between the external built environment characteristics and mental health disorders: multivariable logistic regression analyses.

\begin{tabular}{|c|c|c|c|c|c|}
\hline \multirow{2}{*}{\begin{tabular}{|l} 
Mental health \\
disorder
\end{tabular}} & \multirow{2}{*}{$\begin{array}{l}\text { External environment } \\
\text { characteristics }\end{array}$} & \multirow[t]{2}{*}{$\operatorname{Exp}(\beta)$} & \multicolumn{2}{|c|}{ 95.0\% C.I for $\operatorname{Exp}(\beta)$} & \multirow[t]{2}{*}{$P \leq 0.05$} \\
\hline & & & Lower & Upper & \\
\hline \multirow[t]{2}{*}{ Panic Disorder } & Height of the roof above the ground & 0.027 & 0.003 & 0.247 & 0.001 \\
\hline & Shopping facilities & 3.516 & 1.281 & 9.650 & 0.015 \\
\hline \multirow[t]{2}{*}{ Agoraphobia } & State of roof (leaking or intact) & 0.318 & 0.113 & 0.890 & 0.029 \\
\hline & Shopping facilities & 3.719 & 1.309 & 10.978 & 0.014 \\
\hline${ }^{*}$ SAD & Density of dwelling units & 3.804 & 1.196 & 12.101 & 0.024 \\
\hline${ }^{*} \mathrm{OCD}$ & Shopping facilities & 3.366 & 1.042 & 10.871 & 0.042 \\
\hline \multirow[t]{2}{*}{${ }^{*}$ GAD } & Green spaces & 4.806 & 1.626 & 14.209 & 0.005 \\
\hline & Shopping facilities & 4.372 & 1.160 & 16.476 & 0.029 \\
\hline
\end{tabular}

to the social isolation that characterizes these areas; children who live here are therefore able to adjust better to separation from parents or guardians. Children who reside in the lowincome neighborhoods are exposed to more social interaction and attachment to guardians hence they are likely to experience a higher level of anxiety when separated from their loved ones.

However, the difference in this disorder was not significant in children among the three categories of residential areas. Similarly, there was no significant variation in Separation Anxiety Disorder between the children of middle and high-income houses $\left(\chi^{2}=\right.$ $1.877, P=0.17)$ nor between those of the low and high-income residences $\left(\chi^{2}=2.337, P=0.13\right)$ or the low and middle-income houses $\left(\chi^{2}=0.020, P=0.89\right.$ ). Slightly more female children than male ones experienced this disorder (Table 3). Children who resided in crowded neighborhoods were 3.804 times more susceptible to Separation Anxiety Disorder (SAD) than those who lived in spacious neighborhoods (Table 4).

\section{Obsessive compulsive disorder}

Prevalence of Obsessive Compulsive Disorder (OCD) was found to be significantly different in children of the three residential areas (Table 2). This difference was largely due to the variation in the disorder between the low and high-income residential areas $\left(\chi^{2}=7.781, P=0.005\right)$. The differences in the levels of this disorder in children of the low and middle-income residential areas $\left(\chi^{2}=0.884, P=0.347\right)$ as well as those of the middle and high-income residences $\left(\chi^{2}=3.393, P=0.065\right)$ were insignificant. Gender difference in this disorder was not significant even though the level of the disorder was about $1 \%$ higher in male children compared to female ones (Table 3). Dissatisfaction with shopping facilities led to a 3.366 unit increase in the likelihood of occurrence of OCD in comparison to satisfaction with shopping facilities. There was no significant confounder in relation to OCD.

\section{Generalized anxiety disorder}

Even though the prevalence of Generalized Anxiety Disorder (GAD) was lowest, 5.0\%, in children of the low income residences, the difference in the level of this disorder across the residential areas was not significant. Neither was the difference in incidences of GAD between any two of the categories of residential areas significant (low and middle: $\chi^{2}=2.353, P=0.125$; low and high: $\chi^{2}=1.786, P=0.181$; middle and high: $\chi^{2}=0.037, P=0.848$ ). Male children had a GAD prevalence of $10.3 \%$ compared to females who had a level of $6.6 \%$; this difference was however found to be insignificant.

Children who were dissatisfied with the available green spaces in their residential areas were 4.806 times more prone to GAD in relation to those who were satisfied with green spaces in their areas of residence (Table 4). Similarly, children who were dissatisfied with shopping facilities in their neighborhoods were found to be 4.372 times more susceptible to GAD than those who were satisfied with these facilities.

\section{Discussion and Conclusion}

Characteristics of external built residential environment are important factors in the lives of children as they have 
significant impacts on their mental health. All the roof heights that were less than ten feet were in the low-income residential areas and were made of iron sheets. Low iron sheet roof heights intensify indoor dampness at night by condensing moisture. In the day, they maintain an unbearable high indoor temperature by concentrating sunlight energy. Both of these situations are uncomfortable to occupants and in the long run, can negatively impact mental health. The discomfort is made worse in neighborhoods characterized by overcrowding that tends to limit outdoor activities.

Leaking roofs denote a level of openness and exposure. In this study, housing units that had leaking roofs exposed children to rain water that contributed to indoor dampness which can interfere with sleep at night and cause damage to property. These events as reported by Magea, et al. [19] can lead to anxiety that characterizes agoraphobia particularly where little control of the situation is possible.

Crowded neighborhoods are characterized by high populations, competition for social amenities, possible violence and a perception of reduced possibilities for escape from unwelcome events. Due to these adverse features, children who find themselves in crowded environments tend to cling to their caregivers as a protective measure in anticipation of perceived harm. Quite often, they express a depressed mood that precedes a panic attack and agoraphobia [20].

Green spaces have a positive impact on health through providing areas for social interaction, exercise and relaxation. Ulrich contends that viewing of plants and flowers ameliorates stress in five minutes or less (Ulrich 2002) [18]. Viewing of nature for longer periods creates a sense of calmness that can improve mental health (Ulrich 2002) [18]. Crowded neighborhoods often lack or have less green spaces. Where overcrowding was noted children indicated a near corresponding level of dissatisfaction with green spaces (Table 1). This generated discomfort that increased the likelihood of anxiety disorders.

Dissatisfaction with shopping facilities was responsible for a higher likelihood in the occurrence of panic disorder, agoraphobia, Obsessive Compulsive Disorder and Generalized Anxiety Disorder. In the high-income residential areas, shopping facilities provide opportunity for children's social interaction while in the low-income areas, poverty limits the ability to purchase shop items. Thus, isolation and poverty are social environment characteristics that have important implications on children's mental health.

Policy makers should pay keen attention to the built external environment while practicing equitable development of societies. Physical Planners and public health professionals need to provide guidance to urban physical development particularly in the residential areas. Where populations already exist in poorly built environments, a carefully considered plan of relocation and upgrading of infrastructure and amenities should be instituted. Such upgrading does not necessarily have to involve construction of new improved houses. For a start, modification of available living structures to protect residents from adverse built environment effects through decongesting residential estates by adhering to prescribed housing densities; provision of green spaces, sanitary and garbage management facilities alongside maintenance of access pathways would suffice. Beside these interventions, the economic income of residents should be addressed as it has been noted that improving the built environment without improving the people's income does not yield sustainable outcomes. Poor residents may not consistently pay for amenities and maintenance of improved built environments hence deterioration quickly sets in and a reversal of the situation occur.

A major factor in the existence of poor built residential environment is poverty at individual and local institutional levels. Government policies need to emphasize access to quality housing and reasonable standards of sanitation as fundamental human rights, prioritize neighborhood improvement interventions and work towards reducing populations that live in urban settlements characterized by poor built environmental characteristics.

Whenever, built residential environment improvement activities are undertaken, it would be appropriate to involve the concerned people in the planning processes. Such participatory approaches enhance their sense of ownership and ensure sustainability of the introduced changes; thus municipal authorities should develop institutional mechanisms for people's involvement in the improvement of their built residential environment.

\section{References}

1. Evans GW. The built environment and mental health. Journal of Urban Health. 2003; 80(4): 536-555.

2. Leaderer BP, Belanger K, Triche E, Holford T, Gold DR, Kim Y, et al. Dust mite, cockroach, cat and dog allergen concentrations in homes of asthmatic children in North-Eastern United States: Impact of Socioeconomic Factors and Population Density. Environmental Health Perspective. 2002; 110(4): 419-425.

3. Gifford R. Satisfaction, health, security and social relationships in high-rise buildings. In: Seidel A and Health T (eds.) Social Effects of the Built Environment. London, England: 1984

4. Stewart SE, Rosario MC, Brown TA, Carter AS, Leckman JF, Sukhodolsky D, et al. Principal components and analysis of obsessive compulsive disorder, symptoms in children and adolescents. Biol Psychiatry. 2007; 61(3): 285-91.

5. Ulrich RS. Effects of gardens on health outcomes: theory and research. In: Cooper MC, Barnes M (eds.) Gardens in health care facilities: uses, therapeutic benefits and design recommendations. New York: John Wiley and Sons; 1999. p. 27-86.

6. Ellaway A, Macintyre S, Xavier B. Graffiti, greenery and obesity in adults, secondary analysis of a European cross-sectional survey. BMJ. 2005; 331(7517): 611-612.

7. Baum A, Paulus PB. Crowding. In: Stokols D, Altman I (eds.) Handbook of Environmental Psychology. New York: Wiley; 1987. p. 533-570.

8. Leventhal T, Brooks-Gunn J. Neighbourhoods they live in: The effects of neighborhood residence on child and adolescent outcomes. Psychol Bull. 2000; 126(2): 309-37.

9. Allen D. Impact of our built environment on public health. North Carolina, USA: National Institute of Health Services; 2004. 
10. Ballanda K, Wilde J. Inequalities in perceived health. Dubling: The institute of public health in Ireland. 2003.

11. Hugh B, Marcus G, Richard G. Shaping neighborhoods: a guide for health, sustainability and vitality. London: Spoon Press; 2004.

12. Evans GW, Saltzman H, Cooperman J. Housing quality and children's socio-emotional health. Journal of Environmental Behavior. 2001; 33: 389-399.

13. Lepore SJ, Evans GW, Schneider M. The Dynamic role of social support in the link between chronic stress and psychological distress. Journal of Social Psychology. 1991; 61: 899-909.

14. Sheehan DV, Sheehan KH, Shytle RD, Janavs J, Bannon Y, Rogers JE, et al. The Mini International Neuropsychiatric Interview for children and adolescents (MINI-KID). J Clin Psychiatry. 2010 Mar; 71(3): 313-26. doi: 10.4088/JCP.09m05305whi.

15.World Health Organization. Alcohol, Smoking and Substance
Involvement Screening Test. Geneva, Switzerland: World Health Organization; 1997.

16. World Health Organization. Community Health Nursing. In: Basavanthappa BT, Environmental Health. New Delhi, India: Jaypee Brothers Medical Publishers; 2008.

17. Ministry of Lands. Physical Planning Handbook. Nairobi: Government Printer; 2008

18. Ulrich RS. Health benefits of gardens in hospitals, plants for people. Conference Paper; 2002.

19. Magee WJ, Eaton WW, Wittchen HU, McGonagle KA, Kessler RC. Agoraphobia, simple phobia and social phobia in the national comobidity survey. Arch General Psychiatry. 1996; 53(2): 159-68.

20.American Psychiatric Association. The Diagnostic and Statistical Manual of mental health disorders, fourth edition, DSM-IV-TR ${ }^{\circledR}$. Washington DC; 1994. 